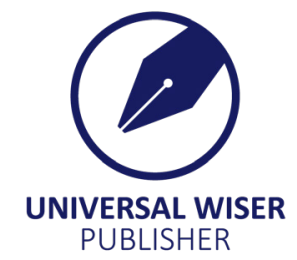

\title{
(PVC / ABS) and Nanocomposite (CAU-10-H) Composite Membrane for Separation of $\mathrm{C}_{2} \mathrm{H}_{6}$ from $\mathrm{CH}_{4}$
}

\author{
Ehsan Kianfar ${ }^{1,2}$ \\ ${ }^{1}$ Department of Chemical Engineering, Arak Branch, Islamic Azad University, Arak, Iran \\ ${ }^{2}$ Young Researchers and Elite Club, Gachsaran Branch, Islamic Azad University, Gachsaran, Iran \\ E-mail: e-kianfar94@iau-arak.ac.ir, ehsan_kianfar2010@yahoo.com
}

\begin{abstract}
In the research, composite membrane derived from Acrylonitrile butadiene styrene (ABS), Polyvinyl chloride (PVC) were prepared with $30 \mathrm{wt} . \%$. In next step, adding $0.125,0.250,0.50 \mathrm{wt} . \%$ of nanocomposite (CAU-10-H) in Acrylonitrile butadiene styrene (ABS), Polyvinyl chloride (PVC) was obtained. All of the polymeric and nanocomposite membranes were e fabricated by the solvent foundry method use a dimethylacetamide solvent. The performance of prepared membranes was calculated for methane and ethane at the feed pressure of 2.5, 3.0, and 3.5 bar at a temperature of $35^{\circ} \mathrm{C}$. Results showed that in most cases, increasing the percentage of Acrylonitrile butadiene styrene (ABS), Polyvinyl chloride (PVC). the permeability of $\mathrm{CH}_{4}$ and $\mathrm{C}_{2} \mathrm{H}_{6}$ increased.
\end{abstract}

Keywords: nanocomposite membranes, gas separation performance, iso-phthalic acid / aluminum nitrate nanocomposite, $\mathrm{PVC} / \mathrm{ABS}$, dimethylacetamide (DMA)

\section{Introduction}

Natural gas has diverse compositions according to different petroleum resources. Methane is the main compound of natural gas since it forms about least $50 \%$ of gas wholly. Also, it consists of some contents of $\mathrm{C}_{2} \mathrm{H}_{6}, \mathrm{C}_{3} \mathrm{H}_{8}, \mathrm{C}_{4} \mathrm{H}_{10}$ and heavier hydrocarbons ${ }^{[1]}$. Natural gas may be either sour or sweet. The sour gas refers to a gas containing such impurities as $\mathrm{H}_{2} \mathrm{~S}$ or $\mathrm{CO}_{2}$. Due to destructive effects including severe wear on transmission pipes and process equipment, all mentioned impurities are refined while production. In addition to mentioned impurities, there are also some neutral gases (mostly nitrogen) in natural gas. Although the presence of nitrogen in natural gas provides no wearing effect on gas transmission and process equipment, it is necessary to be separated from natural gas in production place due to such effects as increased transportation and maintenance costs, decreased the thermal value and environmental issues. Following $\mathrm{CH}_{4}, \mathrm{C}_{2} \mathrm{H}_{6}$ is the second constituent of natural gas ${ }^{[2-3]}$. The difference between natural gases obtained from diverse fields is originated from their ethane content from 1 to $6 \mathrm{wt} \%$. In the past, ethane and greater hydrocarbons were not typically separated from natural gas and they were burned along with $\mathrm{CH}_{4}$ as fuel ${ }^{[4-7]}$. However, this gas- which is so invaluable- is currently extracted through establishing an ethane extraction complex and from natural gas, having a high value for export and providing petrochemical feeds ${ }^{[8-10]}$. The membrane systems are of the best, the most suitable and the most inexpensive separation processes with a high efficiency, which can be a suitable alternative for such complicated and costly operations as absorption, distillation ${ }^{[11-15]}$. Currently, membrane-based separation processes are being replaced by old separation processes such as surface adsorption, centrifuges, etc., on an industrial scale ${ }^{[16-19]}$. Petroleum, gas, and petrochemical industries are of those great industries which are being studied and replaced accordingly ${ }^{[20-22]}$. Although ceramics have been increasingly paid into attention as a membrane due to their considerable chemical and thermal strength, such membranes will not be suitable for separation of the mixtures with the components having similar molecular size since their selectivity is conducted the based on a difference of molecular size ${ }^{[23-25]}$. Additionally, lots of separation processes are conducted in medium operational processes- i.e. under $200^{\circ} \mathrm{C}$ - covering plenty of problems. The capacity of inorganic nanoparticles such as $\mathrm{SiO}_{2}, \mathrm{Al}_{2} \mathrm{O}_{3}, \mathrm{Fe}_{3} \mathrm{O}_{4}, \mathrm{ZrO}_{2}$ and $\mathrm{TiO}_{2}$ inside the polymeric membranes were recognized as a method to improve membranes separation performance ${ }^{[26-30]}$. Among the mentioned nanoparticles, $\mathrm{TiO}_{2}$ is more welcomed due to suitable physical and chemical properties and accessibility as well as potential anti-deposition capabilities ${ }^{[31-34]}$. The nanoparticles $\mathrm{SiO}_{2}$ can be linked to one another and embedded in polymeric membranes by mixing them into membranes

Copyright (C2020 Ehsan Kianfar.

DOI: https://doi.org/10.37256/fce.122020476

This is an open-access article distributed under a CC BY license

(Creative Commons Attribution 4.0 International License)

https://creativecommons.org/licenses/by/4.0/ 
or depositing them on the membrane surface ${ }^{[34]}$. isphthalic acid (PIA) has three major uses:

- PET (PolyEthylene Terephthalate) copolymer, which is used in bottle resins and to a much lesser extent, for fibers. PIA (Purified Is phthalic Acid) reduces the crystallinity of PET, which serves to improve clarity and increase the productivity of bottle-making.

- Unsaturated polyester resins, where the addition of PIA improves thermal resistance and mechanical performance, as well as resistance to chemicals and water.

- Polyester/alkyd surface coating resins, where PIA increases resistance to water, overall durability and weather ability.

Nitrates are excellent precursors for the production of ultra-high purity compounds and certain catalysts and nanoscale (nanoparticles and Nanopowders) materials. Aluminum Nitrate is generally immediately available in most volumes. High purity, submicron, and Nanopowder forms may be considered. We also produce Aluminum Nitrate Solution. American Elements produces to many standard grades when applicable, including Mil Spec (military grade); ACS, Reagent and Technical Grade; Food, Agricultural and Pharmaceutical Grade; Optical Grade, USP and EP/BP (European Pharmacopoeia / British Pharmacopoeia) and follows applicable ASTM testing standards.

In the present study, by adding nanocomposite (CAU-10-H) to the alloy membrane Polyvinyl chloride / acrylonitrile butadiene styrene and fabricating a mixed membrane structure, we tried to enhance the efficiency of this membrane for separation of $\mathrm{CH}_{4}$ and $\mathrm{C}_{2} \mathrm{H}_{6}$ gases.

\section{Experiment}

\subsection{Gas permeability experiment}

In this system, after placing the membrane in the permeability cell, the whole system is under vacuum for half an hour. The upstream part of the gas cell is placed under pressure. By passing the gas through the membrane pressure changes over time will be recorded by the computer. After a period of trial, the tank pressure changes to a steady state and becomes linear. By measuring the slope of the changes and using the equation (1), the permeability of the membrane will be calculated in terms of Barrer.

Figure 1 shows a Schematic of the gas-permeation setup. The pure gas permeability for Mixed Matrix membranes using the equation (1-2) for $\mathrm{CH}_{4}$ and $\mathrm{C}_{2} \mathrm{H}_{6}$ at $35^{\circ} \mathrm{C}^{[1-2]}$ :

$$
\begin{aligned}
& P=\frac{273.15 \times 10^{10} v l}{760 A T\left(\left(p_{0} \times 76\right) / 14.7\right)}\left(\frac{d p}{d t}\right) \\
& 1 \text { Barrer }=\frac{10^{-10} \mathrm{~cm}^{3}(S T P)-\mathrm{cm}}{\mathrm{cm}^{2} . s . c m H g}
\end{aligned}
$$

Where $\mathrm{P}$ is the gas permeability in Barrer $\left(1\right.$ Barrer $\left.=1 \times 10^{-10} \mathrm{~cm}^{3}(\mathrm{STP}) \mathrm{cm} / \mathrm{cm}^{2} \mathrm{~s} \mathrm{cmHg}\right), \mathrm{v}$ refers the volume of the downstream chamber $\left(\mathrm{cm}^{3}\right), 1$ stands the membrane thickness $(\mathrm{cm}), \mathrm{A}$ is effective area of the membrane $\left(\mathrm{cm}^{2}\right)$, and $\mathrm{T}$ is the operating temperature $(\mathrm{K})$. The ideal selectivity for $\mathrm{C}_{2} \mathrm{H}_{6} / \mathrm{CH}_{4}$ was determined by dividing the $\mathrm{CH}_{4}$ and $\mathrm{C}_{2} \mathrm{H}_{6}$ permeability as Eq. (3) ${ }^{[1-2]}$ :

$$
\alpha_{A / B}=\frac{P_{A}}{P_{B}}
$$




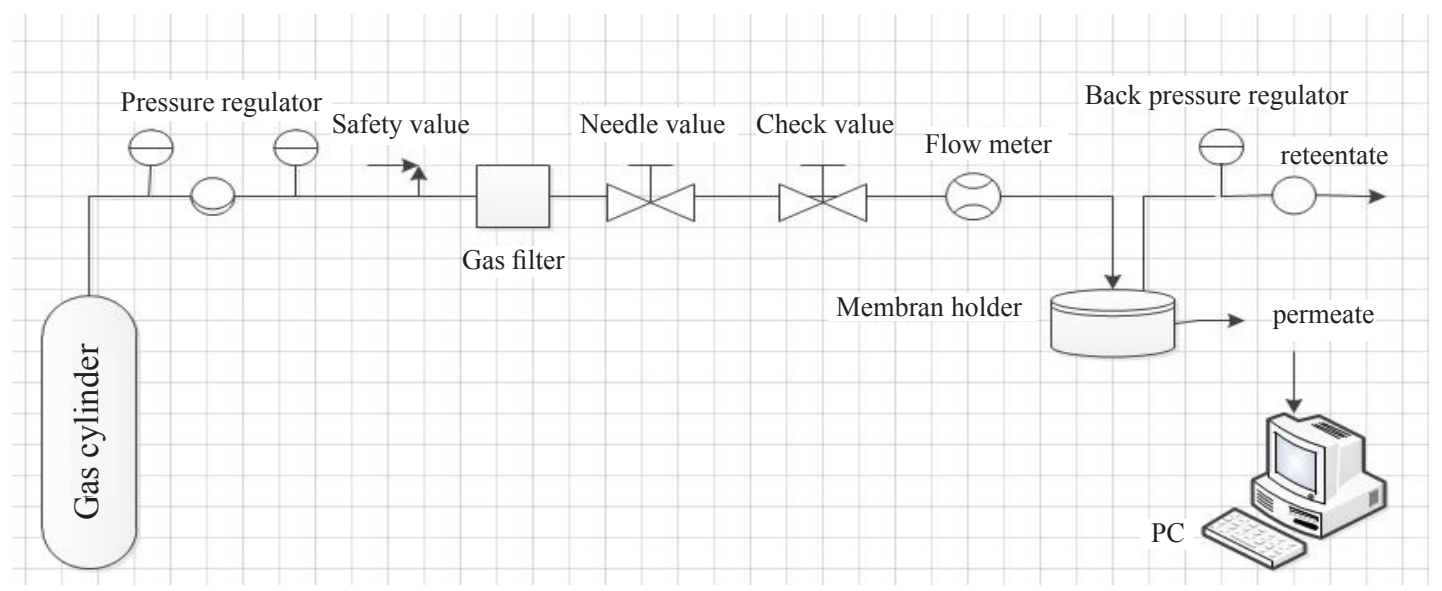

Figure 1. Gas experiment system

\subsection{Preparation of nanocomposite membranes}

The lining method has been used to make nanocomposite membrane. For this purpose, first, the iso-phthalic acid / aluminum nitrate nanocomposite in dimethylacetamide solvent were added to the solvent in different weight percentages of the total weight of the polymer and were stirred well at room temperature for $1 \mathrm{~h}$ until the homogenous solution of nanoparticle-solvent was obtained. Table 1 shows Physical properties of iso-phthalic acid / aluminum nitrate nanocomposite nanoparticles.

Table 1. Physical properties of iso-phthalic acid / aluminum nitrate nanocomposite nanoparticles

\begin{tabular}{cc}
\hline Typical properties & iso-phthalic acid / aluminum nitrate nanocomposite \\
\hline Specific surface area (BET) & $190 \mathrm{~m}^{2} / \mathrm{g}$ \\
Particle size & $5-10 \mathrm{~nm}$ \\
Density & $3.26 \mathrm{~g} / \mathrm{mL}$ \\
Color & White \\
Purity (based on metal) & $>99.9 \%$ \\
\hline
\end{tabular}

\section{Results and discussion}

\subsection{Membranes characterization}

\subsubsection{XRD analysis}

Figure 2 shows the XRD of nanocomposite (CAU-10-H). Peaks in the range of 10-50 $2 \theta$ reflect the crystal structure of (CAU-10-H). According to the XRD pattern database for nanocomposite (CAU-10-H), sharp peaks at 18, 20, 22, 23, 24, $25,272 \theta$ and 30 are the most predominant peaks for calcined $(\mathrm{CAU}-10-\mathrm{H}){ }^{[29]}$. 

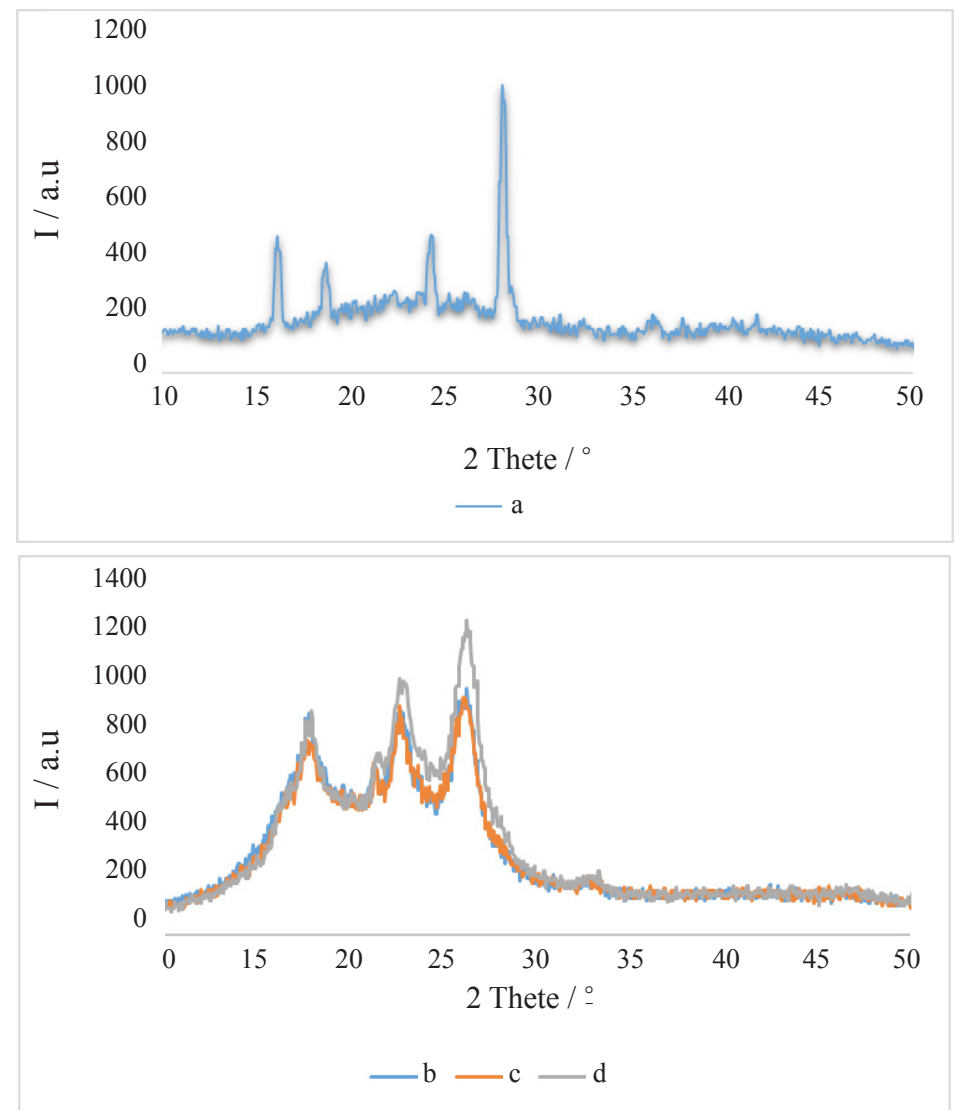

Figure 2. XRD patterns of the Nano, (a) (Nano) (b) (PVC / ABS-\%0.125 (Nano) (c) (PVC / ABS-\%0. 250 (Nano) (d) (PVC / ABS-\% 0. 50 (Nano)

\subsubsection{FTIR analysis}

The FTIR spectra of control and various loading of nanocomposite (CAU-10-H) membrane are shown in Figure 3. High-intensity bands at 699 and $718 \mathrm{~cm}^{-1}$, attributed to C-H-out-of-plane vibrations of the aromatic ring. The top spectrum taken from the edge of the sample shows a broad carbonyl band at $1724.4 \mathrm{~cm}^{-1}$ and broadband for the hydroxyl group and FTIR spectra ABS $600 \mathrm{~cm}^{-1}$ to $1300 \mathrm{~cm}^{-1}$. As discussed, the absorbance bands in virgin ABS corresponding to the trans $\mathrm{C}=$ $\mathrm{C}$ unsaturation (vinyl) at $966.92 \mathrm{~cm}^{-1}$ and $1500-1550 \mathrm{~cm}^{-1}$ and the 1,2 butadiene terminal vinyl C-H band being $911.43 \mathrm{~cm}^{-1}$, decrease considerably for the aged ABS specimen ${ }^{[29]}$.

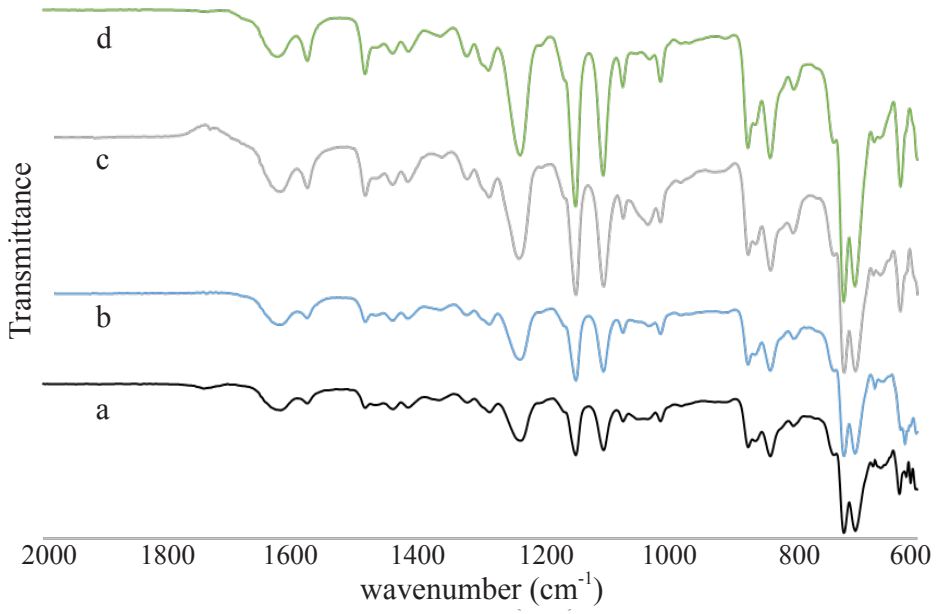

Figure 3. FTIR spectra of the Nano, (a) (Nano) (b) (PVC / ABS-\%0.125 (Nano) (c) (PVC / ABS-\%0. 250 (Nano) (d) (PVC / ABS-\%0. 50 (Nano) 


\subsubsection{SEM, EDX, TEM analysis}

Figure 4 shows SEM images of (CAU-10-H), PVC/ABS-\%0.125(Nano) and PVC/ABS-\%0.250(Nano), PVC / ABS$\% 0.50$ (Nano) samples after calcination. The SEM images of calcined samples confirm that the particles are spherical. After impregnation, on the significant change was observed in the crystal morphology of nanocomposite (CAU-10-H). The TEM images of the nanocomposite (CAU-10-H) shown in Figure 5 further confirmed that the microspheres are formed as a homogeneous aggregation of nanocomposite (CAU-10-H) crystallites.

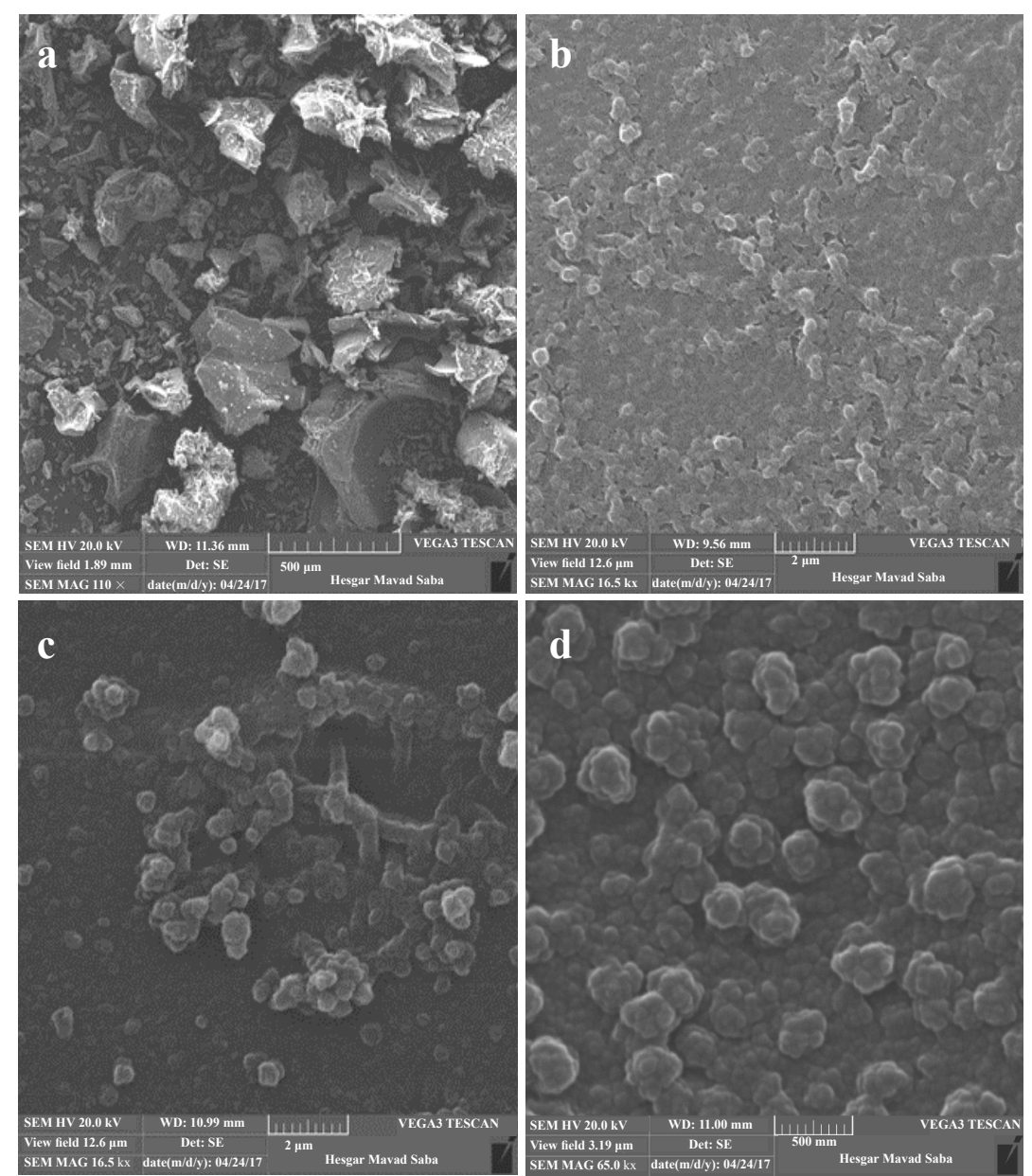

Figure 4. FESEM images of (a) (Nano) (b) (PVC/ABS-\%0.125 (Nano) (c) (PVC/ABS-\%0. 250 (Nano) (d) (PVC/ABS-\%0. 50 (Nano) 

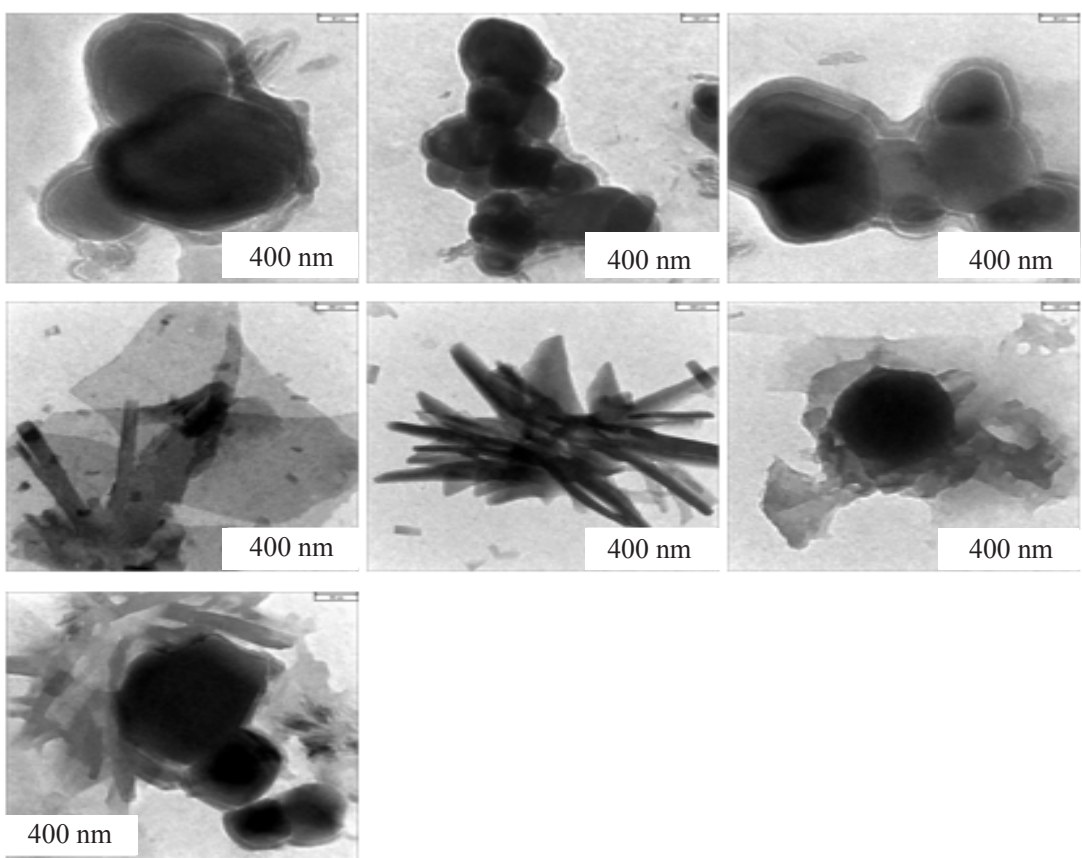

Figure 5. TEM images of the nanocomposite (CAU-10-H)

\section{Results nanocomposite (CAU-10-H) at different pressures}

Results (CAU-10-H) Obtained from PVC and (ABS) + (CAU-10-H) with loading percentage Nanocomposite (CAU10-H) shown in Tables 2-4 and Figures 6-8. Methane and ethane permeability increases by increasing the percentage of Nanocomposite (CAU-10-H) from 0.125 to $0.250 \mathrm{wt} . \%$ in PVC and (ABS) precursor (Figures 6-8). This increase is due to increased permeability of Nanocomposite $(\mathrm{CAU}-10-\mathrm{H})$ in the polymer network and lack of compatibility of Nanocomposite with the polymer caused changes in the intensity of polymer chains and cause the interface between organic polymers and Nanocomposite. Increasing nanoparticle to polymer cause to increase porosity in the membrane. These pores are suitable places for interaction between gases and provide polymer network which helps to increase the influence and gas solubility, and permeability thereby increases. This may denote the dominant contribution of molecular sieving mechanism compared to others that usually complicated in gas molecules transport in nanocomposite membranes in comparison with the polymeric membrane. The selectivity changes of $\mathrm{C}_{2} \mathrm{H}_{6} / \mathrm{CH}_{4}$ by pressure are depicted in Figure 9 . As it can be seen, the selectivity of $\mathrm{C}_{2} \mathrm{H}_{6} / \mathrm{CH}_{4}$ will experience an increasing trend with increased pressure and nanoparticle contents of Isa-phthalic acid /Aluminum Nitrate.

Table 2. Permeability and selectivity of PVC and (ABS) + nanocomposite (CAU-10-H) membrane at a pressure of 2.5 bar

\begin{tabular}{cccc}
\hline Polymer-nanoparticle & $\mathrm{P}_{\mathrm{C} 2 \mathrm{H} 6}$ (barrer) & $\mathrm{P}_{\mathrm{CH} 4}$ (barrer) & $\alpha \mathrm{C}_{2} \mathrm{H}_{6} / \mathrm{CH}_{4}$ \\
\hline PVC / ABS (30Wt\%) & 0.66 & 0.36 & 1.83 \\
$\mathrm{PVC} /$ ABS-\%0.125 (Nano) & 1.25 & 0.63 & 1.98 \\
$\mathrm{PVC} /$ ABS-\%0.250 (Nano) & 1.50 & 0.70 & 2.14 \\
$\mathrm{PVC} /$ ABS-\%0.50 (Nano) & 1.65 & 0.72 & 2.29 \\
\hline
\end{tabular}

Table 3. Permeability and selectivity of PVC and (ABS) + nanocomposite (CAU-10-H) membrane at a pressure of 3 bar

\begin{tabular}{cccc}
\hline Polymer-nanoparticle & $\mathrm{P}_{\mathrm{C} 2 \mathrm{H} 6}$ (barrer) & $\mathrm{P}_{\mathrm{CH} 4}$ (barrer) & $\alpha \mathrm{C}_{2} \mathrm{H}_{6} / \mathrm{CH}_{4}$ \\
\hline PVC / ABS (30Wt \%) & 0.80 & 0.40 & 2.02 \\
PVC / ABS-\%0.125 (Nano) & 1.35 & 0.65 & 2.07 \\
PVC / ABS-\%0.250 (Nano) & 1.60 & 0.71 & 2.25 \\
PVC / ABS-\%0.50 (Nano) & 1.70 & 0.73 & 2.32 \\
\hline
\end{tabular}


Table 4. Permeability and selectivity of PVC and (ABS) + nanocomposite (CAU-10-H) membrane at a pressure of 3.5 bar

\begin{tabular}{cccc}
\hline Polymer-nanoparticle & $\mathrm{P}_{\mathrm{C} 2 \mathrm{H} 6}$ (barrer) & $\mathrm{P}_{\mathrm{CH} 4}$ (barrer) & $\alpha \mathrm{C}_{2} \mathrm{H}_{6} / \mathrm{CH}_{4}$ \\
\hline PVC / ABS (30Wt \%) & 0.85 & 0.41 & 2.07 \\
PVC / ABS-\%0.125 (Nano) & 1.55 & 0.70 & 2.21 \\
PVC / ABS-\%0.250 (Nano) & 1.75 & 0.75 & 2.33 \\
PVC / ABS-\%0.50 (Nano) & 2.3 & 0.80 & 2.87 \\
\hline
\end{tabular}

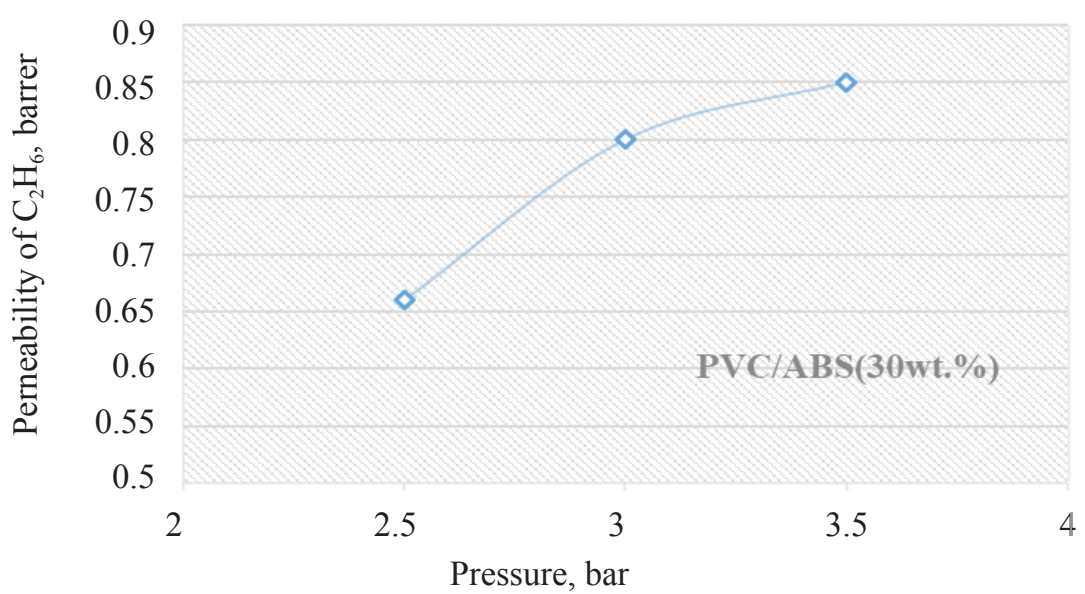

(a)

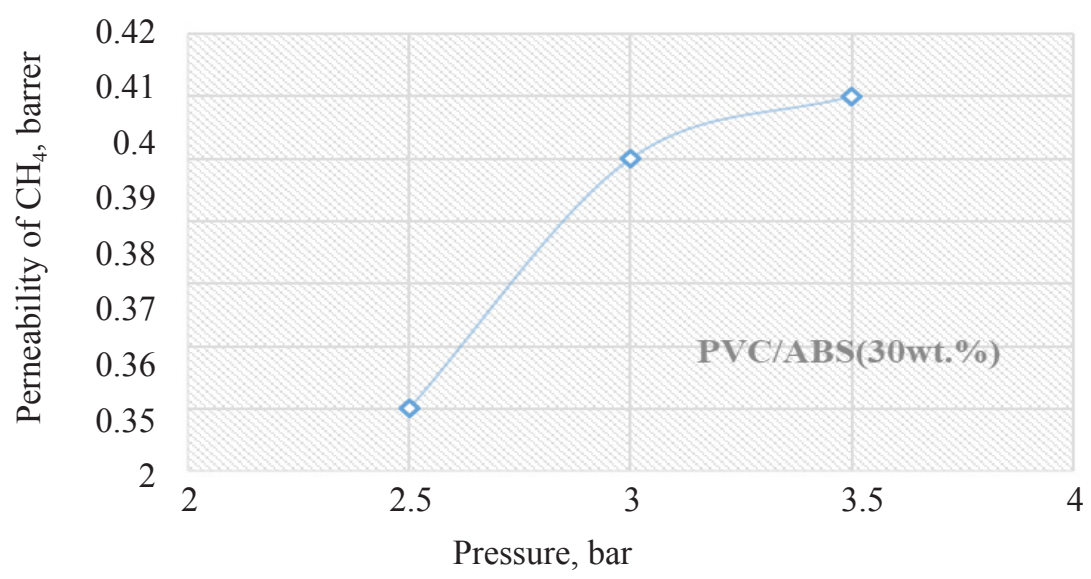

(b)

Figure 6. Permeability of PVC and (ABS))a) $\mathrm{C}_{2} \mathrm{H}_{6}$ and (b) $\mathrm{CH}_{4}$ 


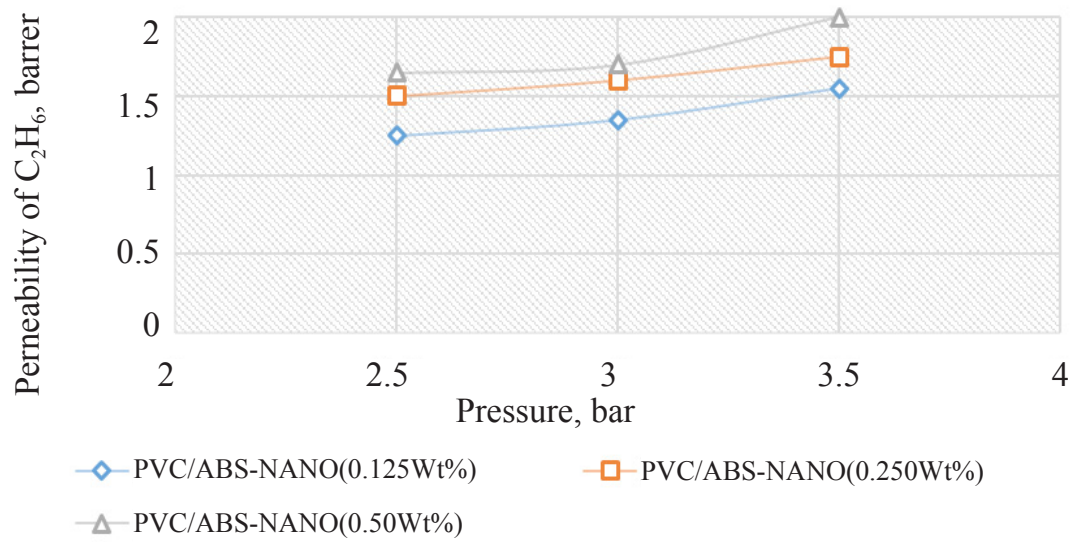

(a)

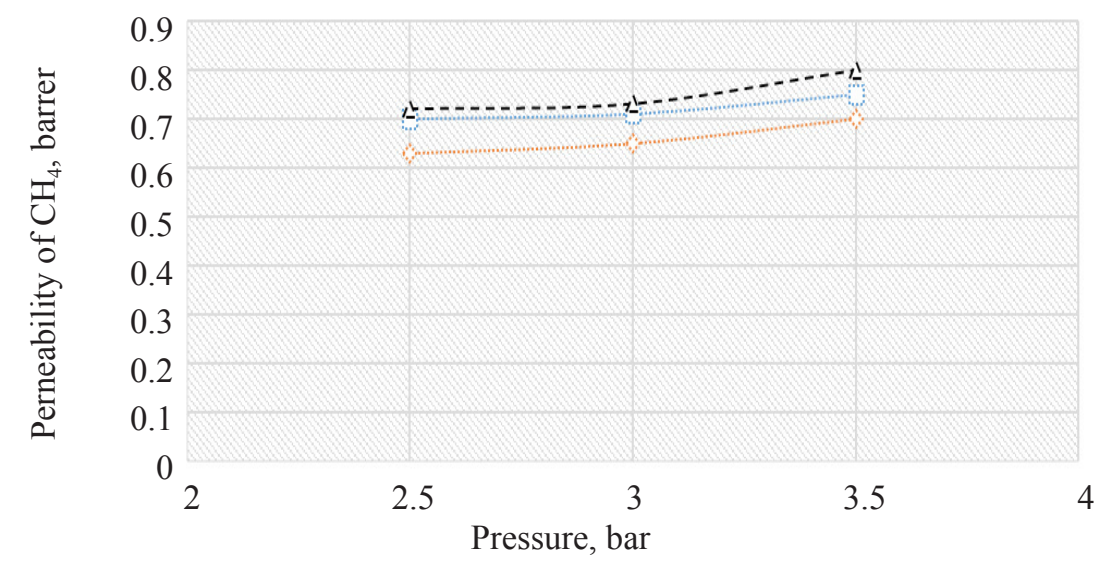

- 그- PVC/ABS-NANO(0.50Wt\%)
- PVC/ABS-NANO(0.125Wt\%)

(b)

Figure 7. $\mathrm{PVC}$ and (ABS) + nanocomposite (CAU-10-H))a) $\mathrm{C}_{2} \mathrm{H}_{6}$ and (b) $\mathrm{CH}_{4}$

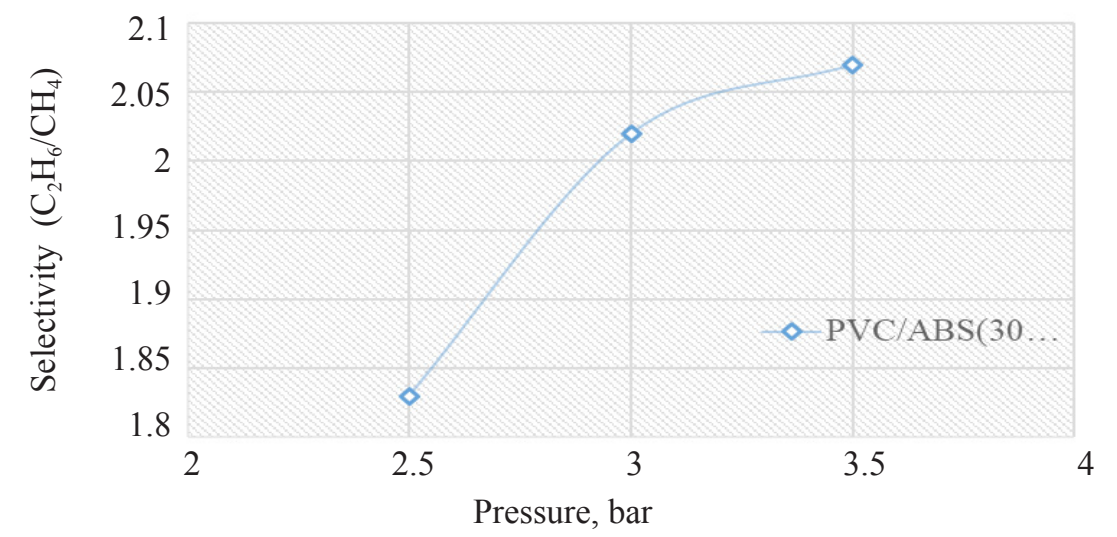

Figure 8. selectivity of $\mathrm{PVC}$ and (ABS) (PVC / $\mathrm{ABS}) \mathrm{C}_{2} \mathrm{H}_{6} / \mathrm{CH}_{4}$ 


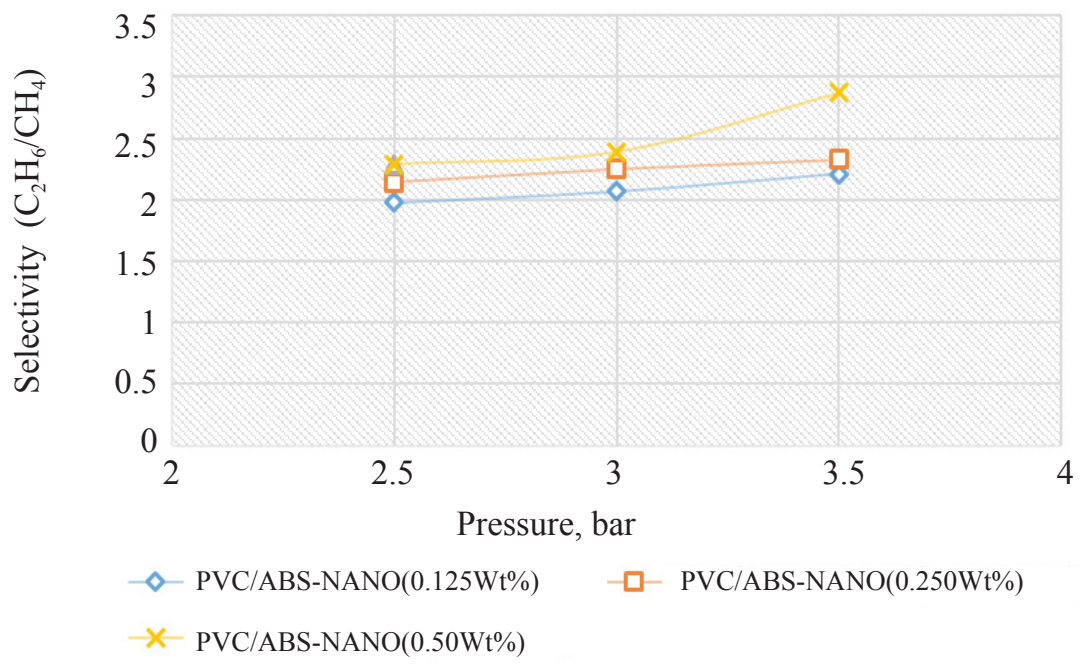

Figure 9. selectivity of PVC and (ABS) + nanocomposite (CAU-10-H) $\mathrm{C}_{2} \mathrm{H}_{6} / \mathrm{CH}_{4}$

\section{Conclusion}

Based on these experiments, the main results are summarized as below:

1. Permeability increases significantly for membranes containing PVC / ABS.

2. Membranes containing carbon or porous organic polymer nanoparticles are more stable.

3. These membranes show increased PVC / ABS selectivity.

4. Permeability of each studied gas is enhanced with the increased pressure of input feedand nanoparticles.

5. Selectivity of $\mathrm{CH}_{4} / \mathrm{C}_{2} \mathrm{H}_{6}$ follows an increase with the increased pressure.

\section{Compliance with ethical standards}

Funding: There is no funding to report for this submission.

Conflict of interest: the authors declare that they have no conflict of interest

\section{References}

[1] Ma H, Hsiao BS, Chu B. Functionalized electrospun nanofibrous microfiltration membranes for removal of bacteria and viruses. J Memb Sci. 2014; 452: 446-452. Available from: doi: 10.1016/j.memsci.2013.10.047.

[2] Wang Z, Yu H, Xia J, et al. Novel GO-blended PVDF ultrafiltration membranes. Desalination. 2012; 299: 50-54. Available from: doi: 10.1016/j.desal.2012.05.015.

[3] Stamatialis DF, Papenburg BJ, Gironés M, et al. Medical applications of membranes: Drug delivery, artificial organs and tissue engineering. J Memb Sci. 2008; 308: 1-34. Available from: doi: 10.1016/j.memsci.2007.09.059.

[4] Dong G, Woo KT, Kim J, et al. Simulation and feasibility study of using thermally rearranged polymeric hollow fiber membranes for various industrial gas separation applications. J Memb Sci. 2015; 496: 229-241. Available from: doi: 10.1016/j.memsci.2015.08.059.

[5] Zhang X, Chen Y, Konsowa AHH, et al. Evaluation of an innovative polyvinyl chloride (PVC) ultrafiltration membrane for wastewater treatment. Sep Purif Technol. 2009; 70: 71-78. Available from: doi: 10.1016/j.seppur.2009.08.019.

[6] Wang C, Wu H, Qu F, et al. Preparation and properties of polyvinyl chloride ultrafiltration membranes blended with functionalized multi-walled carbon nanotubes and MWCNTs / $\mathrm{Fe}_{3} \mathrm{O}_{4}$ hybrids. 2016; 43417: 1-8. Available from: doi: 10.1002/app.43417.

[7] Roy KJ, Anjali TV., Sujith A. Asymmetric membranes based on poly(vinyl chloride): effect of molecular weight of additive and solvent power on the morphology and performance. J Mater Sci. 2017; 52: 5708-5725. Available from: doi: 10.1007/s10853-017-0807-1.

[8] Xu J, Xu Z-LL. Poly (vinyl chloride) (PVC) hollow fiber ultrafiltration membranes prepared from PVC / additives / solvent. J Memb Sci. 2002; 208: 203-212. Available from: doi: 10.1016/S03767388(02)00261-2.

[9] Teow YH, Ooi BS, Ahmad AL. Fouling behaviours of $\mathrm{PVDF}-\mathrm{TiO}_{2}$ mixed-matrix membrane applied to humic acid treatment. J Water Process Eng. 2016. Available from: doi: 10.1016/j.jwpe.2016.03.005.

[10] Gao W, Liang H, Ma J, et al. Membrane fouling control in ultra filtration technology for drinking water production: A 
review. DES. 2011; 272: 1-8. Available from: doi: 10.1016/j.desal.2011.01.051.

[11] Sadeghi M, Chenar MP, Rahimian M, et al. Gas permeation properties of polyvinylchloride / polyethyleneglycol blend membranes. 2008; 1-6. Available from: doi: 10.1002/app.

[13] Behboudi A, Jafarzadeh Y, Yegani R. Polyvinyl chloride / polycarbonate blend ultrafiltration membranes for water treatment. J Memb Sci. 2017; 534: 18-24. Available from: doi: 10.1016/j.memsci.2017.04.011.

[14] Yang YF, Wan LS, Xu ZK. Surface hydrophilization for polypropylene microporous membranes: A facile interfacial crosslinking approach. J Memb Sci. 2009; 326: 372-381. Available from: doi: 10.1016/j.memsci.2008.10.011.

[15] Rabiee H, Mahdi S, Shahabadi S, et al. Enhancement in permeation and antifouling properties of PVC ultrafiltration membranes with addition of hydrophilic surfactant additives: Tween-20 and Tween-80. Journal of Environmental Chemical Engineering. 2016; 4: 4050-4061. Available from: doi: 10.1016/j.jece.2016.09.015.

[16] Fan X, Su Y, Zhao X, et al. Fabrication of polyvinyl chloride ultrafiltration membranes with stable antifouling property by exploring the pore formation and surface modification capabilities of polyvinyl formal. J Memb Sci. 2014; 464: 100-109. Available from: doi: 10.1016/j.memsci.2014.04.005.

[17] Yong L, Wahab A, Peng C, et al. Polymeric membranes incorporated with metal / metal oxide nanoparticles: A comprehensive review. DES. 2013; 308: 15-33. Available from: doi: 10.1016/j.desal.2010.11.033.

[18] Rabiee H, Vatanpour V, Farahani MHDA, et al. Improvement in flux and antifouling properties of PVC ultrafiltration membranes by incorporation of zinc oxide $(\mathrm{ZnO})$ nanoparticles. Sep Purif Technol. 2015; 156: 299-310. Available from: doi: 10.1016/j.seppur.2015.10.015.

[19] Zhang Y, Cui P, Du T, et al. Development of a sulfated Y-doped nonstoichiometric zirconia / polysulfone composite membrane for treatment of wastewater containing oil. Sep Purif Technol. 2009; 70: 153-159. Available from: doi: 10.1016/j.seppur.2009.09.010.

[20] Ng LY, Leo CP, Mohammad AW. Optimizing the incorporation of silica nanoparticles in polysulfone / poly (vinyl alcohol) membranes with response surface methodology. J Appl Polym Sci. 2011; 121: 1804-1814. Available from: doi: 10.1002/app.33628.

[21] Yang Y, Zhang H, Wang P, et al. The influence of nano-sized $\mathrm{TiO}_{2}$ fillers on the morphologies and properties of PSF UF membrane. J Memb Sci. 2007; 288: 231-238. Available from: doi: 10.1016/j.memsci.2006.11.019.

[22] Yuanyuan Zhao, Jiaqi Lu, Xuyang Liu, et al. Performance enhancement of polyvinyl chloride ultrafiltration membrane modified with graphene oxide. J Colloid Interface Sci. 2016; 480: 1-8. Available from: doi: 10.1016/j.jcis.2016.06.075.

[23] Dorosti F, Omidkhah MR, Pedram MZ, et al. Fabrication and characterization of polysulfone / polyimide-zeolite mixed matrix membrane for gas separation. Chem Eng J. 2011; 171: 1469-1476. Available from: doi: 10.1016/ j.cej.2011.05.081.

[24] Goh PS, Ismail AF, Sanip SM, et al. Recent advances of inorganic fillers in mixed matrix membrane for gas separation. Sep Purif Technol. 2011; 81: 243-264. Available from: doi: 10.1016/j.seppur.2011.07.042.

[25] Shah R, Gale JD, Payne MC. Comparing the acidities of zeolites and SAPOs from first principles. Chem Commun. 1997; 131-132. Available from: doi: 10.1039/a605200b.

[26] Hoek EM V, Ghosh AK, Huang X, et al. Physical-chemical properties, separation performance, and fouling resistance of mixed-matrix ultrafiltration membranes. Desalination. 2011; 283: 89-99. Available from: doi: 10.1016/j.desal.2011.04.008.

[27] Han R, Zhang S, Liu C, et al. Effect of NaA zeolite particle addition on poly (phthalazinone ether sulfone ketone) composite ultrafiltration (UF) membrane performance. J Memb Sci. 2009; 345: 5-12. Available from: doi: 10.1016/ j.memsci.2009.07.052.

[28] Li JF, Xu ZL, Yang H, et al. Effect of $\mathrm{TiO}_{2}$ nanoparticles on the surface morphology and performance of microporous PES membrane. Appl Surf Sci. 2009; 255: 4725-4732.

[29] Kianfar E, Pirouzfar V, Sakhaeinia H. An experimental study on absorption / stripping $\mathrm{CO}_{2}$ using Mono-ethanol amine hollow fiber membrane contactor. J. Taiwan Inst. Chem. Eng. 2017; 80: 954 -962.

[30] Salimi M, Pirouzfar V, Kianfar E. Enhanced gas transport properties in silica nanoparticles filler polystyrene nanocomposite membranes. Colloid Polym. Sci. 2017; 295: 215 -226.

[31] Salimi M, Pirouzfar V, Kianfar E. Novel nanocomposite membranes prepared with PVC / ABS and silica nanoparticles for $\mathrm{CH}_{4} / \mathrm{C}_{2} \mathrm{H}_{6}$ separation. Polymer Science, Series A. 2017; 59(4): 566-574.

[32] Ehsan Kianfar, Mahmoud Salimi, Farshid Kianfar, et al. $\mathrm{CO}_{2} / \mathrm{N}_{2}$ separation using polyvinyl chloride iso-phthalic acid / aluminium nitrate nanocomposite membrane. Macromolecular Research. 2019; 27(1): 83-89.

[33] Ehsan Kianfar. Recent advances in synthesized, properties, applications of Nano zeolites. Journal of Sol-Gel Science and Technology. 2019; 91(2): 415-429.

[34] E kianfar. Microchemical Journal. 2019. Available from: https://doi.org/10.1016/j.microc.2020.104822. 